\section{Adjustable sutures: who needs them?}

\author{
Eye (2003) 17, 683-684. doi:10.1038/ \\ sj.eye. 6700466
}

Why do ophthalmologists enjoy performing cataract surgery? Because it is a nice neat operation with very little blood (usually) and in $92 \%$ of cases, a predictable outcome. ${ }^{1}$ In strabismus surgery the outcome is not as predictable. The same operation for a similar angle of deviation may yield differing results in different patients. This is especially true of complex squints such as reoperations, restrictive myopathies and innervational abnormalities, where alterations in muscle elasticity, length-tension ratios, and contractures affect the calculation. The surgical goal aims to balance satisfactory alignment with good ocular rotations and minimal sensory symptoms. These goals may not be attainable in equal measure and the surgeon may then be left with a compromise. For instance, one may aim for alignment in the primary position at the expense of normal ocular rotations or accept a slight undercorrection to prevent diplopia. Adjustable sutures are undoubtedly useful in these situations as they extend the surgery into the postoperative period, enabling an assessment and alteration to be made to the final result.

Although adjustable suture strabismus surgery was first described by Claude Worth in 1908 , it was popularised following Jampolsky's ${ }^{2,3}$ descriptions in the 1970s. Initially, they were not widely accepted. Some studies ${ }^{4}$ showed that alignment on the first postoperative day was not predictive of final alignment and therefore argued against their usefulness. Certainly, long-term drift is similar in both adjustable and nonadjustable suture surgery, but adjustable sutures do enable the eyes to be placed in a position that best anticipates the drift pattern. ${ }^{5,6}$ Relative indications for adjustable sutures have included reoperations, ${ }^{2}$ muscle pathology such as thyroid ophthalmopathy, ${ }^{7}$ and innervational

abnormalities, but their usefulness in primary squint surgery has been a contentious point. Although conventional calculations yield more

NDL George

predictable motor alignment, many surgeons feel more comfortable with the facility of postoperative adjustment because of the unpredictability of the patients' sensory adaptations in longstanding squint. Overall, around $40-50 \%$ of patients require adjustment postoperatively. $5,6,8$ Surprisingly, although the technique is now widely employed among strabismus surgeons, there have been no randomised controlled trials on the use of adjustable sutures. Indeed, such a trial may be difficult to perform as the surgical goals, such as alignment, good ocular rotations and the absence of diplopia, vary in different patients. In this month's issue, Tripathi et al ${ }^{9}$ in their provocatively titled paper 'Strabismus surgery: Adjustable sutures-good for all?' show a reoperation rate of $27 \%$ in the nonadjustable suture group as compared to $8.5 \%$ in the adjustable suture group. While one should be wary of crude outcome measures in unmatched groups, these figures seem to bear out findings in previous studies. Other studies, using alignment within 10 prism dioptres as an outcome measure, have shown success rates of 69-80\%.,6 As Keech et al ${ }^{5}$ pointed out, alignment and reoperation rates do not necessarily correlate. Some patients who have an alignment outside 10 prism dioptres may be significantly improved from their preoperative angle such that they consider the surgery a success. Other patients with only a small angle residual deviation may have postoperative diplopia that requires reoperation.

However, are adjustable sutures really good for all? There are specific concerns regarding the inferior rectus muscle. A progressive overcorrection develops in $40-50 \%$ of adjustable inferior rectus recessions, while this complication is rarely seen in nonadjustable surgery. ${ }^{10}$ Some surgeons now avoid adjustable inferior rectus surgery or at least use a nonabsorbable suture. It is also noteworthy that $66 \%$ of patients in Tripathi's study declined to have adjustable sutures for unspecified reasons, ${ }^{9}$ illustrating that the patient's choice and psychological profile are still important factors to consider.
Department of Ophthalmology Ninewells Hospital Dundee, UK

Correspondence: NDL George Department of Ophthalmology Ninewells Hospital Dundee DD1 9SY, UK Tel: + 441382496469 Fax: + 441382632893 E-mail: nick.george@ tuht.scot.nhs.co.uk 
Preoperative counselling of strabismus patients is as important as the surgery itself. Consideration of adjustable sutures should be given to most cases. The information given in this and other studies forms a useful guide for both surgeon and patient.

\section{References}

1 Desai P, Minassian DC, Reidy A. The National Cataract Survey 1997/98: a report of the results of the clinical outcomes. Br J Ophthalmol 1999; 83: 1336-1340.

2 Jampolsky A. Strabismus reoperation techniques. Trans Am Acad Ophthalmol Otolaryngol 1975; 79: 704-711.

3 Jampolsky A. Current techniques of adjustable strabismus surgery. Am J Ophthalmol 1979; 88: 406-418.

4 Cassin B, Serianni N, Romano P. The change in ocular alignment between the first day and six weeks following eye muscle surgery. Am Orthoptic J 1986; 36: 99-107.
5 Keech RV, Scott WE, Christensen LE. Adjustable suture strabismus surgery. J Pediatr Ophthalmol Strabismus 1987; 24 97-102.

6 Weston B, Enzenauer RW, Kraft SP, Gayowsky GR. Stability of the postoperative alignment in adjustable-suture strabismus surgery. J Pediatr Ophthalmol Strabismus 1991; 28: 206-211.

7 Lueder GT, Scott WE, Kutschke PJ, Keech RV. Long term results of adjustable suture surgery for strabismus secondary to thyroid ophthalmopathy. Ophthalmology 1992; 99: 993-997.

8 Wisnicki HJ, Repka MX, Guyton DL. Reoperation rate in adjustable strabismus surgery. J Pediatr Ophthalmol Strabismus 1988; 25: 112-114.

9 Tripathi A, Haslett R, Marsh IB. Strabismus surgery: adjustable sutures - good for all. Eye 2003; 17: 739-742.

10 Sprunger DT, Helveston EM. Progressive overcorrection after inferior rectus recession. J Pediatr Ophthalmol Strabismus 1993; 30: 145-148. 